\title{
Especificitat i variabilitat de les habilitats comunicatives i lingüístiques en infants amb TEA: recursos digitals per a la intervenció
}

\author{
Àlex Escolà Serra ${ }^{1,3}$, Cristina Aguilar Basés ${ }^{1,2}$, Cristina \\ Mumbardó-Adam $1,3,4$ \\ ${ }^{1}$ Institut Diagnòstic i d'Atenció Psiquiàtrica i Psicològica (IDAPP), ${ }^{2}$ Logopèdia i \\ Psicologia Interdisciplinar Vincles, 3Universitat Oberta de Catalunya, 4FPCEE \\ Blanquerna. Universitat Ramon Llull \\ autismind@gmail.com \\ cmumbardoa@uoc.edu \\ cristinaab3@blanquerna.url.edu
}

Recepció: 20/04/2020, acceptació: 01/09/2020

Resum: La intervenció amb infants amb dificultats en comunicació i llenguatge implica necessàriament ajustar els materials $\mathrm{i}$ les eines disponibles a les especificitats comunicatives i lingüístiques de cada infant. Ara bé, en el cas d'infants amb trastorn de l'espectre de l'autisme (TEA), la variabilitat existent en les dificultats de comunicació i llenguatge requereixen un coneixement i una comprensió extensos del perfil lingüístic d'aquests infants, així com dels recursos existents, per a una intervenció exitosa que respongui a les seves necessitats i interessos. Així, l'objectiu d'aquest article resideix a descriure les principals alteracions del llenguatge i la comunicació dels infants amb TEA i presentar un recull de recursos digitals per a la intervenció, així com una reflexió entorn del seu ús.

Paraules clau: Trastorn de l'espectre de l'autisme, perfil lingüístic, recursos digitals.

Especificidad y variabilidad de las habilidades comunicativas y lingüísticas en niños con TEA: recursos digitales para la intervención

Resumen: La intervención con ninos y niñas con dificultades en comunicación y lenguaje implica necesariamente ajustar los materiales y herramientas disponibles a sus especificidades comunicativas y lingüísticas. En el caso de niños y niñas con Trastorno del Espectro del Autismo (TEA), la variabilidad existente en las dificultades de comunicación y lenguaje requiere de un conocimiento y comprensión extenso del perfil lingüístico de estos niños y niñas, así como de los recursos existentes para una intervención exitosa que responda a sus necesidades e intereses. Así, el objetivo del presente artículo reside al describir las principales alteraciones del lenguaje y la comunicación de los niños y niñas con TEA y presentar una compilación de recursos digitales para la intervención, así como una reflexión sobre su uso.

Palabras clave: Trastorno del Espectro del Autismo, perfil lingüístico, recursos digitales. 
Abstract: Intervention in children with language and communication disorders necessarily involves an adjustment of the available materials and tools to their communicative and linguistic specificities. However, for children with Autism Spectrum Disorder (ASD), the existing variability in communication and language difficulties requires an extensive knowledge and understanding of these children's linguistic profiles, as well as the existing materials and tools for intervention, so that the latter can be tailored to the children's needs and interests. The objective of this paper is thus to describe the main variations in language and communication among children with ASD and to present useful digital materials and resources for intervention.

Keywords: Autism Spectrum Disorder, linguistic profile, digital resources.

\section{INTRODUCCIÓ}

La variabilitat fenotípica pròpia del trastorn de l'espectre de l'autisme (TEA) comporta una àmplia diversitat en el funcionament de les persones amb TEA. Aquesta mateixa diversitat es fa vigent en les seves competències comunicatives i lingüístiques. Si bé les dificultats en comunicació i interacció social, és a dir, en l'ús del llenguatge en situacions socials (pragmàtica) és una de les característiques nuclears del TEA, aquestes dificultats tenen un impacte en els altres components del llenguatge, donada la correlació i la influència recíproca que cada component té sobre els altres. D'altra banda, en alguns infants amb TEA s'observen dificultats en el llenguatge que no s'expliquen a causa del TEA ni per l'impacte del TEA en les habilitats comunicatives i lingüístiques de la persona. El coneixement i la comprensió del perfil comunicatiu i lingüístic en els infants amb TEA resulta crucial per ajustar la intervenció a les seves necessitats i interessos.

En aquesta línia, en els darrers anys s'ha començat a introduir l'ús de recursos digitals, com ara aplicacions per a tauletes o programes d'ordinador, en el treball amb infants amb TEA. Diferents estudis n'avalen l'eficàcia, ja que s'obtenen resultats favorables en l'adquisició de vocabulari (Khowaja i Salim 2019); l'expressió oral (Martin et al. 2019), i resulten una eina amb un efecte positiu molt significatiu en l'adquisició general d'aprenentatges (Aspiranti, Larwin i Schade 2020). Tot i així, l'èxit d'una intervenció en comunicació i llenguatge mediada per noves tecnologies dependrà, en gran mesura, de l'elecció d'un recurs adequat així com d'un mètode d'implementació que s'ajusti a les necessitats de l'infant i les seves característiques. És per això que resulta imprescindible conèixer, d'una banda, els perfils comunicatius i lingüístics existents en el TEA i, d'altra banda, els diversos recursos digitals disponibles per tal de poder seleccionar els més adients i garantir una major eficàcia en la intervenció.

\section{Els PERFils DE LLENGUATGE EN infants Amb TEA}

La gran variabilitat de manifestacions fenotípiques dins del TEA també s'estén en l'àmbit de la comunicació i el llenguatge. Tot i que en aquest apartat ens centrarem principalment a descriure el perfil lingüístic dels infants que desenvolupen llenguatge oral, no deixa de ser cert que alguns infants presenten un retard en l'adquisició del llenguatge i altres no arriben a desenvolupar un llenguatge oral funcional, sobretot aquells amb una discapacitat intel-lectual associada, per la qual cosa requereixen l'ús de Sistemes Augmentatius i/o Alternatius de Comunicació (SAAC) (Iacono, Trembath i Erickson 2016).

El perfil lingüístic d'infants amb TEA (sense discapacitat intel-lectual associada) es caracteritza per una adquisició dels aspectes estructurals del llenguatge, amb dificultats 
marcades en els aspectes funcionals del llenguatge, és a dir, en l'ús que se'n fa. Solen presentar dificultats tant de llenguatge comprensiu com expressiu (Kwok, Brown, Smyth i Cardy 2015), tot i que en els primers anys de vida el perfil comprensiu sembla estar més afectat que l'expressiu (Davidson i Weismer 2017). Les dificultats de comprensió i interacció socials pròpies de la simptomatologia TEA s'acompanyen, en el pla lingüístic, de dificultats en el llenguatge abstracte, en la identificació de la intencionalitat del parlant, en la comprensió d'actes indirectes i en la realització d'inferències per accedir a la informació que no s'obté de manera explícita, entre d'altres (Martos 2001, Monsalve 2001). Pel que fa a les altres àrees del llenguatge, la fonètica i la fonologia, no acostumen a estar alterades, tot i que s'observen alteracions en l'ús i la comprensió d'elements prosòdics de la parla. Els infants amb TEA també tenen dificultats en el lèxic i la semàntica, lligades a les seves dificultats de comprensió social i pragmàtiques, ja que principalment presenten dificultats amb les paraules polisèmiques i homònimes, en l'ús de vocabulari abstracte i de verbs cognoscitius, com per exemple pensar, creure i considerar (Martos i Ayuda 2002). En aquest sentit, els infants amb TEA no solen fer ús del context lingüístic ni extralingüístic per al processament de la informació, emfatitzant així dificultats en l'ús del coneixement semàntic de paraules i oracions (Belinchón, Igoa i Rivière 1992). En relació amb la morfosintaxi, solen fer un ús correcte de les normes morfosintàctiques, tot i que s'evidencien dificultats amb els morfemes temporals i personals dels verbs i en els pronoms i d'elements díctics. L'ús de díctics es relaciona directament amb les habilitats pragmàtiques i la comprensió del context, ja que es necessita la interpretació d'aquest tant per entendre com per emprar correctament els díctics (Martos i Ayuda 2002).

Les habilitats lingüístiques manifesten una enorme heterogeneïtat en els infants amb TEA. Quan parlem del subgrup d'infants amb TEA que mostren dificultats en el llenguatge que no s'expliquen pel quadre simptomatològic relacionat amb el TEA, ens referim a infants amb TEA que presenten dificultats de llenguatge pròpies del perfil típic d'infants amb TEL/TDL (trastorn específic del llenguatge/trastorn del desenvolupament del llenguatge), i que tenen més dificultats lingüístiques que van més enllà de les descrites en el paràgraf anterior.

Un estudi recent suggereix tres subgrups classificatoris pel que fa a les habilitats lingüístiques dels infants amb TEA: aquells amb unes habilitats lingüístiques dins de la normalitat, tot i les dificultats en la pragmàtica del llenguatge pròpia del quadre simptomatològic del TEA, aquells amb marcada dificultat en la producció gramatical però vocabulari relativament intacte i aquells amb habilitats lingüístiques més afectades tant des d'un punt de vista lèxic com semàntic i sintàctic (Wittke, Mastergeorge, Ozonoff, Rogers i Naigles 2017). Aquest darrer grup sol presentar dificultats en la construcció i planificació sintàctica, així com una disminució en l'ús de morfemes gramaticals, i una elevada probabilitat d'ús d'ecolàlies o d'argot. Totes aquestes dificultats es podrien trobar també en infants amb TEL/TDL. Per consegüent, el perfil lingüístic dels infants amb TEA que presenten dificultats pròpies de TEL/TDL es caracteritza per dèficits en el llenguatge estructural, en comparació amb infants amb TEL/TDL o TEA (Lloyd, Paintin i Botting 2006), i una alteració més significativa en l'ús funcional del llenguatge. En aquest sentit, i pel que fa a les habilitats pragmàtiques, mostren un perfil semblant als infants amb TEA i una major afectació en aquesta àrea en comparació amb la població amb TEL/TDL (Loucas et al. 2008). En efecte, en la població d'infants amb TEL/TDL, les dificultats en comunicació i interacció social solen estar relacionades amb un funcionament social deteriorat (Loucas et al. 2008). Finalment, a diferència dels infants amb TEL/TDL, els infants amb TEA i dificultats pròpies de TEL/TD no acostumen a presentar dificultats en la fonètica i la fonologia (Kjelgaard i Tager-Flusberg 2001; Lloyd et al. 2006), tot i que s'han observat similituds en les dificultats en la memòria fonològica (Tager-Flusberg i Joseph 
2003). No obstant això, en alguns casos s'observen dificultats en la parla (com per exemple dislàlies) i en l'organització fonològica de la parla.

\section{RECURSOS DIGITALS PER A LA INTERVENCIÓ}

Existeixen molts recursos digitals per afavorir el desenvolupament del llenguatge i la comunicació, però el nombre es redueix quan es tracta d'aplicacions pensades per a la intervenció d'infants amb TEA. A continuació es comenten algunes aplicacions i programes per estimular diferents àrees del llenguatge i la comunicació dels infants amb TEA, centrant-nos en l'ús de tauletes per l'accessibilitat i la funcionalitat actual que tenen aquests dispositius. Algunes d'aquestes eines han estat específicament dissenyades per a la població amb TEA, tenint en compte les característiques i necessitats pròpies d'aquesta condició; altres inclouen la participació d'adults amb TEA i les seves famílies en el procés de creació i desenvolupament de les aplicacions, en estreta col-laboració amb experts en autisme, aportant un valor inestimable al recurs. També s'anomenen algunes aplicacions més generalistes, però que reuneixen les condicions adients per utilitzar-les amb infants amb TEA, ja que inclouen, per exemple, moltes possibilitats de configuració per poder personalitzar l'experiència, imprescindible per adaptar el recurs a la idiosincràsia de cada usuari.

Alguns recursos com l'aplicació mòbil \#SoyVisual (Tropical S.C. 2006) ofereixen multitud d'exercicis i jocs descarregables de manera gratuïta, pensats per estimular els diferents nivells i components del llenguatge tant comprensiu com expressiu: comprensió del llenguatge oral, estructura de frases (component morfosintàctic), lèxic i semàntica $i$ també comunicació funcional. És una eina dissenyada específicament per a infants amb TEA, amb una interfície molt clara, senzilla i fàcil d'utilitzar i un suport visual en totes les activitats proposades que facilita l'execució dels diferents reptes presentats. Espacio Onda (Onda educa 2002) és una plataforma digital en línia dirigida a famílies i professionals com a suport per al treball sistemàtic dels diferents components del llenguatge. També ofereix un programa que permet fer un avaluació inicial de cada component del llenguatge per determinar el perfil lingüístic actual de l'infant, a partir del qual s'obté la programació del pla terapèutic i se’n fa una avaluació continuada. La plataforma destaca pel seu treball sistematitzat, per la gran quantitat i varietat de recursos que facilita per generalitzar els aprenentatges i per les ajudes d'accés als continguts, atenent a la seqüència evolutiva de cada etapa i a les necessitats pròpies de cadascuna.

En aquesta línia, caldria esmentar també els recursos que ofereix Special iApps, fundada per donar suport a infants amb necessitats educatives especials. Entre les seves aplicacions destaca Palabras Especiales (Special iApps 2011), una app pensada per treballar lectoescriptura, però que també ofereix moltes possibilitats per estimular el llenguatge comprensiu, la morfosintaxi i la pragmàtica. Ofereix sis modalitats diferents d'exercicis, (veu, text, imatge...) però el que realment fa d'aquesta aplicació un recurs valuós és la possibilitat d'editar el contingut, afegint noves paraules i creant nous exercicis, per ajustarlos a les necessitats individuals de cada infant. Existeixen altres eines per crear contingut que també poden ser útils; tot i requerir un temps previ de dedicació per preparar els exercicis, ja que permeten una intervenció més personalitzada. Un altre exemple és l'app Make it: crea juegos educativos (Learny Land 2018), que, tot i estar més centrada en els aprenentatges acadèmics, possibilita la creació de moltes activitats per abordar les dificultats de llenguatge dels nens i nenes amb TEA.

Mita (ImagiRation LLC 2020) és una aplicació dirigida a població d'edat precoç que treballa l'àrea cognitiva i de llenguatge. L'aplicació es basa en evidències científiques que demostren que l'augment de les habilitats per respondre a diferents estímuls de forma 
simultània afavoreix l'aprenentatge global i redueix les conductes d'hiperselecció de certs estímuls. L'aplicació ofereix un pla estructurat de sis activitats diàries amb un reforçador final i permet fer un seguiment de l'evolució de l'infant. Les activitats plantejades s' adapten automàticament en funció del progrés del subjecte.

AbaPlanet (Fundación Planeta Imaginario 2015) és una aplicació específica per a l'estimulació del llenguatge comprensiu de persones amb TEA. Centrada a treballar el llenguatge comprensiu, en concret l'adquisició de vocabulari, segueix els principis bàsics d'aprenentatge de la metodologia ABA (Applied Behavior Analysis), i de forma automàtica s'adapta al ritme de l'infant, augmentant la complexitat de la demanda quan aquest demostra que ha integrat un nou concepte o reduint l'exigència si la resposta no és l'esperada. Podem trobar altres aplicacions dedicades a afavorir la comprensió, com ara Dictapicto (Fundación Orange 2019), que tradueix a l'instant la veu a pictogrames, per fer més accessible la informació verbal per als infants amb TEA, oferint un suport visual que els permet processar millor el missatge i integrar els diferents conceptes. Altres aplicacions no específiques per a infants amb TEA però que poden resultar útils són ILexis HD Pro (Venedettini 2013), Léxico cognición, (Pappy GmbH 2016) o Talk around it español (Neuro Hero Ltd 2014), que estan pensades per incrementar el lèxic, però també permeten el treball de la morfosintaxi i la consciència fonològica, entre d'altres. Per afavorir el llenguatge expressiu i comprensiu, i components específics com ara la morfosintaxi i la semàntica, existeixen aplicacions com Conversation Therapy (Tactus Therapy Solutions Ltd 2014), que presenta imatges sobre diferents temes i planteja diferents preguntes per reflexionar-hi. Altres com Dado Historia (Cachucha developer 2020), Toontastic 3D (Google Llc 2017) o eTABU: Juego Social (Softnauts 2019) són alguns exemples de jocs que fomenten el llenguatge expressiu en àmbit morfosintàctic $\mathrm{i}$ narratiu de manera lúdica.

Pel que fa a la pragmàtica, disposem de recursos com l'app AutisMIND (Idapp Mind 2016), que està pensada per afavorir la comunicació social i la Teoria de la Ment per a infants amb TEA. Es focalitza a ajudar l'infant a posar-se en el lloc de l'altre, entendre què està pensant, sentint, i desenvolupar la capacitat d'inferir estats mentals a través del llenguatge no verbal, el context i la interpretació global de la situació. Existeixen altres recursos molt interessants, com ara l'app Social Bunch: perspectives, (First words 2015), The Social Express II (The Language Express Inc. 2014) o Social Detective (Social Skill Builder 2015), però actualment només es troben en anglès.

Finalment, cal esmentar que també existeixen eines molt interessants per treballar la parla, des d'aplicacions senzilles per practicar el buf fins a d'altres molt completes per al treball de la fonètica, per exemple Articulation Station Pro Es (Little Bee Speech 2020). De la mateixa manera, comptem amb multitud de comunicadors dinàmics per a tauleta, pensats per a infants no verbals que necessiten un sistema augmentatiu o alternatiu de la comunicació, però en aquest article ens hem focalitzat en aquells recursos que poden ser de més utilitat per als perfils descrits en el punt anterior.

\section{CONCLUSIONS. L'ÚS DELS RECURSOS DigitAls AMB INFANTS AMB TEA}

En aquest article s'han definit els principals perfils lingüístics en la població d'infants amb TEA, així com els recursos digitals existents per a la intervenció. L'ús d'eines digitals haurà de tenir presents les habilitats de comunicació i llenguatge de cada infant, així com les seves pròpies característiques, necessitats, interessos i el context. Les noves tecnologies solen ser extremadament motivadores per a la majoria d'infants $i$, particularment, per als infants amb TEA, ja que presenten un entorn predictiu i controlable, amb una estimulació 
a través de diferents canals sensorials, interfícies dinàmiques i lúdiques i un feedback immediat. Donada la gran versatilitat dels programes i aplicacions, l'ús d'aquests recursos digitals en infants amb TEA facilita, per una banda, l'ajust al perfil d'aprenentatge d'aquesta població, ja que integren (o es poden configurar) elements com l'estructura, l'ús de reforçadors personalitzats, l'aprenentatge sense error i l'ús predominant d'elements visuals. D'altra banda, l'ús de recursos digitals possibilita també controlar variables que dificulten els processos d'aprenentatge en infants amb TEA, ja que permeten controlar, per exemple, la quantitat d'estímuls presents en les interfícies per tal d'eliminar elements distractors i facilitar l'atenció cap a l'estímul objectiu.

Ara bé, l'ús de la tecnologia per se no és suficient per produir canvis en els infants amb TEA, ja que el més important són les estratègies desenvolupades a través de la tecnologia (Passerino i Santarosa 2008). De fet, l'ús arbitrari d'aplicacions sense una avaluació prèvia de l'usuari i el context, que tingui en compte les necessitats i particularitats de l'infant, pot arribar a tenir efectes iatrogènics derivats del mal ús o l'abús. En aquest sentit, l'Acadèmica Americana de Pediatria ha publicat una guia de recomanacions quant a l'ús i el consum de contingut multimèdia en població infantil (AAP 2018) que pot ser d'utilitat per establir uns criteris de bones pràctiques en l'ús de recursos digitals amb infants. Tot i així, cal tenir en compte les particularitats i necessitats dels infants amb TEA, que requereixen una valoració exhaustiva que permeti seleccionar el recurs més adient, així com més supervisió i suport en la implementació d'aquest. A més a més, cal tenir en compte que una eina tecnològica no reemplaça mai cap tècnica d'estimulació, sinó que es limita a ser una alternativa més d'ajuda dins d'un conjunt d'elements a la seva disposició (Ferreyra, Méndez, \& Rodríguez, 2009).

Com a conclusió, per poder fer un bon ús dels recursos digitals en el treball de la comunicació i el llenguatge en infants amb TEA, cal conèixer els diferents perfils lingüístics i la variabilitat de les seves dificultats, tenir en compte el context de l'infant, les seves característiques personals i els seus interessos i motivacions, i definir uns objectius terapèutics individualitzats. Finalment, caldrà escollir els recursos digitals que més s'ajustin a les necessitats de l'infant, implementant-los segons els criteris de bones pràctiques en l'ús de recursos digitals.

\section{REFERÈNCIES BIBLIOGRÀFIQUES}

American Academy of Pediatrics (2018). Children and Media Tips from American Academy of Pediatrics [en línia]. <https://www.aap.org/en-us/about-the-aap/aap-pressroom/news-features-and-safety-tips/Pages/Children-and-Media-Tips.aspx> [Consulta: 19 abril 2020].

Aspiranti, KathleEn B.; Larwin, Karen H.; SCHAde, Benjamin P. (2020). «iPads/tablets and students with autism: A meta-analysis of academic effects». Assistive Technology, 32(1), 23-30, https://doi.org/10.1080/10400435.2018.1463575

Belinchón, Mercedes; Rivière, Ángel; IgOA, José Manuel (1992). «Psicología del lenguaje». Investigación y teoría, 4.

DAVIDSON, MEgan M.; WeISMER, SUSAN ElLiS (2017). «A discrepancy in comprehension and production in early language development in ASD: Is it clinically relevant? ». Journal of autism and developmental disorders, 47(7), 2163-2175. <https://doi.org/10.1007/s10803017-3135-Z> [Consulta: 19 abril 2020].

Ferreyra, José Alberto; Méndez, Amalia; Rodrigo, María (2009). «El uso de las TiC en la Educación Especial: Descripción de un Sistema Informático para Niños Discapacitados Visuales en Etapa Preescolar». Revista Iberoamericana de Tecnología en Educación y Educación en Tecnología, 3, 55-62. 
Iacono, Teresa; Trembath, David; Erickson, Shane (2016). «The role of augmentative and alternative communication for children with autism: corrent status and future trends». Neuropsychiatric disease and treatment, 12, 2349-2361. <https://doi.org/10.2147/NDT.S95967> [Consulta: 19 abril 2020].

KHOWAJA, KAMran; SALIM, Siti SALWAH (2019). «Serious Game for children with autism to learn vocabulary: an experimental evaluation». International journal of human-computer interaction, 35(1), 1-26.

KJELGAARD, MARGARET M.; TAgER-FluSBERG, Helen (2001). «An investigation of language impairment in autism: Implications for genetic subgroups». Language and cognitive processes, 16(2-3), 287-308. <https://doi.org/10.1080/01690960042000058> [Consulta: 19 abril 2020].

KwoK, Elaine Y. L.; Brown, Heather M.; Smyth, Rachael E.; Cardy, Janis Oram (2015). «Meta-analysis of receptive and expressive language skills in autism spectrum disorder». Research in Autism Spectrum Disorders, 9, 202-222. <https://doi.org/10.1016/j.rasd.2014.10.008> [Consulta: 19 abril 2020].

Loucas, Tom; Charman, Tony; Pickles, Andrew; Simonoff, Emily; Chandler, Susie; MELDRUM, DAVID; BAIRD, GILLIAN (2008). «Autistic symptomatology and language ability in autism spectrum disorder and specific language impairment». Journal of Child Psychology and Psychiatry, 49(11), 1184-1192. <https://doi.org/10.1111/J.14697610.2008.01951.X> [Consulta: 19 abril 2020].

Lloyd, Helen; Paintin, Kath; Botting, Nicola (2006). «Performance of children with different types of communication impairment on the Clinical Evaluation of Language Fundamentals (CELF)». Child Language Teaching and Therapy, 22(1), 47-67. <https://doi.org/10.1191/0265659006CT2970A> [Consulta: 19 abril 2020].

Martin, Estefania; Cupeiro, Carlos; Pizarro, Laura; Roldán-Álvarez, David; MONTERO-DE-EsPINOSA, GUADALUPE (2019). «"Today I Tell” A Comics and Story Creation App for People with Autism Spectrum Condition». International Journal of HumanComputer Interaction, 35(8), 679-691, <https://doi.org/10.1080/10447318.2018.1550178> [Consulta: 19 abril 2020].

MARTOS, J.; AYUDA, R. (2002). «Comunicación y lenguaje en el espectro autista: el autismo y la disfasia». Revista de neurología, 34(1), 58-63.

Monsalve, CARmen (2001). «Comunicación y lenguaje en autismo: claves para el buen trabajo de un logopeda». Martos Pérez, JuAn; PÉREZ Julià, MARISA (ed.). Autismo. Un enfoque orientado a la formación en logopedia. NAU Llibres.

Passerino, Liliana M.; Santarosa, Lucila M. C. (2008). "Autism and digital learning environments: Processes of interaction and mediation». Computers \& Education, 51(1), 385-402.

TAger-Flusberg, Helen; Joseph, Robert M. (2003). «Identifying neurocognitive phenotypes in autism». Philosophical Transactions of the Royal Society of London. Series B: Biological Sciences, 358(1430), 303-314. <https://doi.org/10.1098/rstb.2002.1198> [Consulta: 19 abril 2020].

Wittke, Kacie; Mastergeorge, Ann M.; Ozonoff, Sally; Rogers, Sally J.; Naigles, LETITIA R. (2017). «Grammatical language impairment in autism spectrum disorder: Exploring language phenotypes beyond standardized testing». Frontiers in psychology, 8 , 532. <https://doi.org/10.3389/fpsyg.2017.005.32> [Consulta: 19 abril 2020]. 